\title{
Characterization of One-Year Progression of Risk Phenotypes of Diabetic Retinopathy
}

\author{
Luísa Ribeiro - Inês P. Marques - Rita Coimbra • Torcato Santos • \\ Maria H. Madeira • Ana Rita Santos • Patrícia Barreto • \\ Conceição Lobo · José Cunha-Vaz
}

Received: October 18, 2021 / Accepted: November 18, 2021 / Published online: December 5, 2021

(C) The Author(s) 2021

\section{ABSTRACT}

Introduction: We characterized the progression of different diabetic retinopathy (DR) phenotypes in type 2 diabetes (T2D).

Methods: A prospective longitudinal cohort study (CORDIS, NCT03696810) was conducted with three visits (baseline, 6 months, and 1

L. Ribeiro $(\bowtie) \cdot$ I. P. Marques · R. Coimbra ·

T. Santos - M. H. Madeira - A. R. Santos .

P. Barreto · C. Lobo · J. Cunha-Vaz $(\bowtie)$

AIBILI-Association for Innovation and Biomedical Research on Light and Image, Coimbra, Portugal e-mail: mlribeiro@aibili.pt

J. Cunha-Vaz

e-mail: cunhavaz@aibili.pt

L. Ribeiro - I. P. Marques · M. H. Madeira .

A. R. Santos - C. Lobo · J. Cunha-Vaz

Coimbra Institute for Clinical and Biomedical

Research (iCBR), Faculty of Medicine, University of

Coimbra, Coimbra, Portugal

L. Ribeiro · I. P. Marques · M. H. Madeira .

A. R. Santos · C. Lobo · J. Cunha-Vaz

Center for Innovative Biomedicine and

Biotechnology (CIBB), University of Coimbra, 3000-

548 Coimbra, Portugal

C. Lobo

Department of Ophthalmology, Centro Hospitalar e Universitário de Coimbra (CHUC), Coimbra, Portugal

A. R. Santos

Department of Orthoptics, School of Health,

Polytechnic of Porto, Porto, Portugal year). Demographic and systemic data included age, sex, diabetes duration, lipid profile, and hemoglobin A1c (HbA1c). Ophthalmological examinations included best-corrected visual acuity (BCVA), color fundus photography (CFP), and optical coherence tomography (OCT and OCTA). Phenotype classification was performed at the 6-month visit based on microaneurysm turnover (MAT, on CFP) and central retinal thickness (CRT, on OCT). Only risk phenotypes $\mathrm{B}$ (MAT $<6$ and increased CRT) and $\mathrm{C}$ (MAT $\geq 6$ with or without increased CRT) were included. ETDRS grading was performed at the baseline visit based on seven-field CFP.

Results: A total of 133 T2D individuals were included in the study; 81 (60\%) eyes were classified as phenotype B and 52 (40\%) eyes as phenotype C. Of these, 128 completed the 1-year follow-up. At baseline, eyes with phenotype $\mathrm{C}$ showed greater capillary closure (superior capillary plexus, deep capillary plexus, and full retina, $p<0.001)$ and increased foveal avascular zone (FAZ) area $(p<0.001)$, indicating more advanced microvascular disease. Neurodegeneration represented by thinning of the ganglion cell layer + inner plexiform layer (GCL + IPL) was present in both phenotypes. When analyzing the 1-year progression of each phenotype, only phenotype $C$ revealed a significant decrease in BCVA $(p=0.02)$ and enlargement of the FAZ $(p=0.03)$. A significant progressive decrease in the vessel density of the deep capillary layer and in MAT occurred in both phenotypes, but these 
changes were particularly relevant in phenotype $\mathrm{C}$ and ETDRS grades 43-47. During the 1-year period, both phenotypes $\mathrm{B}$ and $\mathrm{C}$ showed progression in GCL + IPL thinning $(p<0.001)$.

Conclusions: In the 1-year period of follow-up, both phenotypes $\mathrm{B}$ and $\mathrm{C}$ showed progression in retinal neurodegeneration, whereas phenotype $\mathrm{C}$ showed more marked disease progression at the microvascular level.

Keywords: Diabetes; Retinopathy; Capillary closure; Neurodegeneration

\section{Key Summary Points}

Why carry out this study?

An unmet need

Identification of the eyes of individuals with type 2 diabetes (T2D) and acceptable metabolic control that are at risk for diabetic retinopathy (DR) progression.

The aim of the study was to characterize disease progression in a 1-year period in different risk phenotypes of DR.

\section{What was learned from the study?}

Both risk phenotypes $\mathrm{B}$ and $\mathrm{C}$ showed progression in retinal neurodegeneration, but phenotype $\mathrm{C}$ was associated with greater capillary closure and microvascular disease progression.

The baseline characterization of DR phenotype in T2D individuals is a good indicator of DR progression, and this study shows that individuals with phenotype $\mathrm{C}$ show more rapid progression, needing a closer follow-up.

\section{INTRODUCTION}

As a major complication of diabetes mellitus and leading cause of vision loss in the world, diabetic retinopathy (DR) is a serious ophthalmic condition, with a major influence on quality of life and a huge socioeconomic impact $[1,2]$.

The etiology of DR is complex and remains to be clarified, as many individuals with diabetes do not develop vision-threatening retinal changes, maintaining good visual acuity throughout their lives, whereas others show progression to the two major vision-threatening complications, diabetic macular edema (DME) and proliferative diabetic retinopathy (PDR) [3]. Understanding these inter-individual differences is fundamental to the ability to identify the retinal lesions and their dynamics in the earlier stages of DR and correlate their occurrence with the progression of DR to visionthreatening complications in order to facilitate a more personalized intervention in each patient.

Through the years, it has been generally accepted that diabetes duration and level of metabolic control play a role in the inter-individual differences observed in diabetic individuals, but this cannot explain the variability observed in DR evolution [4]. Associations have been established between DR incidence and progression and systemic factors such as glycemic control, arterial hypertension, inflammatory and/or lipid levels, and lifestyle [5]. Still, in a recent report we have shown that ocular markers may be more informative to predict disease progression in individuals with wellcontrolled diabetes [6].

Indeed, using hierarchical cluster analysis in 376 eyes of diabetic individuals, our group identified three different phenotypes of nonproliferative DR (NPDR) based on the characteristics of the retinal lesions, namely microaneurysm turnover (MAT) and central retinal thickness (CRT) [7], that appear to be associated with different levels of risk for the development of macular edema [8] or DR progression [9]. Briefly, phenotype A is characterized by low MAT $(<6)$ and normal CRT, phenotype B by low MAT $(<6)$ and increased CRT, and phenotype $\mathrm{C}$ by higher MAT $(\geq 6)$.

Importantly, when evaluating the 5-year risk association of DR phenotypes with the development of vision-threatening complications, 
we reported that phenotype A identified eyes at very low risk for vision-threatening complications, whereas phenotypes $\mathrm{B}$ and $\mathrm{C}$ presented higher risk, with phenotype $\mathrm{C}$ being the only one associated with the development of PDR [8].

This new prospective 1-year study of a large cohort of patients with type 2 diabetes (T2D) therefore aims to further characterize these two risk phenotypes, $\mathrm{B}$ and $\mathrm{C}$, at both the systemic and ocular levels, using only noninvasive examination methodologies that are easily used in clinical practice.

\section{METHODS}

This prospective longitudinal interventional cohort study (CORDIS; ClinicalTrials.gov identifier NCT03696810) was designed to conduct a 1-year follow-up in individuals with T2D with NPDR (levels 20, 35, 43, and 47, in the Early Treatment Diabetic Retinopathy Study [ETDRS] severity scale [10]) at demographic, systemic, and ophthalmological levels. The tenets of the Declaration of Helsinki were followed, and the study was reviewed and approved by the AIBILI [Association for Innovation and Biomedical Research on Light and Image] Ethics Committee for Health with the number CEC/194/18 (CORDIS). Written informed consent to participate in the study was provided by each participant, after all procedures were explained.

Individuals were included according to specified inclusion criteria, namely classification as phenotype $\mathrm{B}$ or $\mathrm{C}$ of $\mathrm{DR}$, and exclusion criteria, and were followed for three visits: baseline (V0), 6 months (V1), and 12 months (V2). The study exclusion criteria comprised the presence of cataract or other disease that may interfere with fundus examinations, glaucoma, any eye surgery within a period of 6 months before the baseline visit, other retinal vascular disease, any previous laser treatment or intravitreal injections, or dilation of pupil $<5 \mathrm{~mm}$. Eyes with baseline central thickening identifying center-involved macular edema (CIME), defined as retinal thickness (RT) $\geq 290 \mu \mathrm{m}$ in women and $\geq 305 \mu \mathrm{m}$ in men [11], were also excluded.
A total of 133 people with T2D were included, comprising men $(99,74 \%)$ and women (34, $26 \%$ with diagnosed adult-onset of T2D, aged 47 to 79 years (Table 1 ).

At the baseline visit (V0), demographics including age, duration of diabetes, comorbidities, and concomitant medication were collected for each participant. Physical assessment with biometric measures (body weight and height) and blood pressure evaluation were performed by an experienced nurse. Laboratory analyses included plasma concentrations of hemoglobin $\left(\mathrm{HbA}_{1 \mathrm{c}}\right)$, lipid fractionation identifying total cholesterol, high-density lipoprotein (HDL), low-density lipoprotein (LDL), and triglycerides, measured to assess metabolic control.

Participants underwent a complete eye examination, which included best-corrected visual acuity (BCVA), slit-lamp examination, intraocular pressure measurement, color fundus photography (CFP), optical coherence tomography (OCT), and optical coherence tomography angiography (OCTA).

The study eye was selected at 6 the-month visit, based on the inclusion/exclusion criteria, namely phenotype classification $\mathrm{B}$ and $\mathrm{C}$ defined by 6 -month MAT and CRT.

During the period of the study and outside of the study visits, participants were followed in our institution in accordance with usual clinical practice.

The calculation of the sample size was based on previous studies [7, 12-14], where the existence of three distinct phenotypes of DR progression in T2D was proposed. Their incidence in the DR population was $50 \%$ for phenotype A, $25 \%$ for phenotype $B$, and $25 \%$ for phenotype C. Baseline characteristics of the study population are presented in Table 1.

An age-matched healthy control population of 84 individuals was used as reference for demographic and ocular variables.

\section{Best-Corrected Visual Acuity Evaluation}

BCVA was assessed and recorded as letters read at $4 \mathrm{~m}$ on ETDRS charts. The final BCVA letter score was calculated by adding the number of 
Table 1 Baseline demographic, systemic, and ocular characteristics of each phenotype at baseline

\begin{tabular}{|c|c|c|c|}
\hline & $\begin{array}{l}\text { Phenotype B } \\
(N=\mathbf{8 1})\end{array}$ & $\begin{array}{l}\text { Phenotype C } \\
(N=52)\end{array}$ & $\begin{array}{l}p \text { value (between phenotypes B } \\
\text { and C) }\end{array}$ \\
\hline Gender, male/female $N(\%)$ & $57 / 24(70 \% / 30 \%)$ & $42 / 10(81 \% / 19 \%)$ & $0.180^{1}$ \\
\hline Age (years), mean $\pm S D$ & $\begin{array}{l}68.0 \pm 6.5 \\
\left(p=0.660^{2}\right)^{*}\end{array}$ & $\begin{array}{l}65.9 \pm 6.7 \\
\left(p=\mathbf{0 . 0 1 6 ^ { 2 }}\right)^{*}\end{array}$ & $0.083^{2}$ \\
\hline Diabetes duration (years), mean $\pm S D$ & $19.1 \pm 7.7$ & $19.8 \pm 7.3$ & $0.307^{2}$ \\
\hline BMI $\left(\mathrm{kg} / \mathrm{m}^{2}\right)$ & $28.9 \pm 4.1$ & $29.8 \pm 4.6$ & $0.313^{2}$ \\
\hline HbAlc (\%) & $7.5 \pm 1.3$ & $8.0 \pm 1.4$ & $0.013^{2}$ \\
\hline Total cholesterol (mg/dL) & $166.9 \pm 42.6$ & $155.3 \pm 41.3$ & $0.187^{2}$ \\
\hline LDL cholesterol (mg/dL) & $94.7 \pm 33.9$ & $86.5 \pm 33.7$ & $0.137^{2}$ \\
\hline HDL cholesterol (mg/dL) & $46.9 \pm 11.2$ & $42.5 \pm 11.5$ & $0.033^{2}$ \\
\hline Triglycerides (mg/dL) & $126.5 \pm 55.7$ & $131.9 \pm 70.1$ & $0.964^{2}$ \\
\hline Systolic blood pressure $(\mathrm{mmHg})$ & $136.0 \pm 12.2$ & $136.4 \pm 13.3$ & $0.942^{2}$ \\
\hline Diastolic blood pressure $(\mathrm{mmHg})$ & $70.1 \pm 8.3$ & $69.9 \pm 6.8$ & $0.972^{2}$ \\
\hline Level 20 & $12(14.81 \%)$ & $2(3.85 \%)$ & $<0.001^{1}$ \\
\hline Level 35 & $56(69.14 \%)$ & $22(42.31 \%)$ & \\
\hline Levels $43+47$ & $13(16.05 \%)$ & $28(53.85 \%)$ & \\
\hline BCVA (logMAR) & $0.01 \pm 0.08$ & $0.02 \pm 0.10$ & $0.579^{2}$ \\
\hline $\mathrm{CRT}(\mu \mathrm{m})$ & $282.5 \pm 14.3$ & $266.9 \pm 23.1$ & $<0.001^{2}$ \\
\hline GCL + IPL thickness $(\mu \mathrm{m})$ & $80.7 \pm 7.4$ & $78.4 \pm 8.7$ & $0.200^{2}$ \\
\hline MA turnover ${ }^{a}$ & $1.3 \pm 1.6$ & $11.7 \pm 7.0$ & $<0.001^{2}$ \\
\hline $\begin{array}{l}\text { Vessel density: inner ring_SCP } \\
(\mathrm{mm}-1)\end{array}$ & $21.01 \pm 1.07$ & $19.99 \pm 1.62$ & $<0.001^{2}$ \\
\hline $\begin{array}{l}\text { Vessel density: inner ring-DCP } \\
(\mathrm{mm}-1)\end{array}$ & $16.13 \pm 2.07$ & $14.94 \pm 2.53$ & $0.005^{2}$ \\
\hline $\begin{array}{l}\text { Vessel density: inner ring—full retina } \\
(\mathrm{mm}-1)\end{array}$ & $22.67 \pm 1.06$ & $21.72 \pm 1.46$ & $<0.001^{2}$ \\
\hline FAZ area $(\mathrm{mm} 2)$ & $0.20 \pm 0.08$ & $0.28 \pm 0.10$ & $<0.001^{2}$ \\
\hline
\end{tabular}

Bold values represent statistically significant changes, with $p<0.05$, using the ${ }^{1}$ Chi-square test or ${ }^{2}$ Mann-Whitney test. ${ }^{a}$ Assessed at visit 1 (6 months)

$N$ number of participants, $S D$ standard deviation, $B C V A$ best-corrected visual acuity, $C R T$ central retinal thickness, $B M I$ body mass index, ETDRS Early Treatment Diabetic Retinopathy Study, GCL + IPL ganglion cell layer + inner plexiform layer, $L D L$ low-density lipoprotein, $H D L$ high-density lipoprotein, $F R$ full retina, $D C P$ deep capillary plexus, $S C P$ superior capillary plexus, $F A Z$ foveal avascular zone, $H b A l c$ glycated hemoglobin 
letters read at $4 \mathrm{~m}$ plus 30 (or the number of letters read at $1 \mathrm{~m}$ ). BCVA was evaluated using the Snellen scale and converted into logarithm of the minimum angle of resolution (logMAR) [15]. The presence of any visual loss was recorded.

\section{Color Fundus Photography, ETDRS, and Microaneurysm Classification}

Early Treatment Diabetic Retinopathy Study (ETDRS) classification was performed based on seven-field CFP images obtained at $30 / 35^{\circ}$ using a Topcon TRC-50DX camera (Topcon Medical Systems, Tokyo, Japan) with a resolution of $3596 \times 2448$ pixels. The ETDRS grading scale and the DR severity score were classified at Coimbra Ophthalmology Reading Center (CORC), using a modified Airlie House classification scheme according to the ETDRS protocol [10]. Classification was performed by two graders, with an inter-grader agreement of $97 \%$ (15).

Microaneurysm (MA) classification was automatically performed on $45 / 50^{\circ}$ two-field images using RetmarkerDR (Retmarker SA, Coimbra, Portugal), a computer-aided diagnostic software program that performs MA earmarking and identification of macular red dotlike vascular lesions, and allows the comparison of the same eye within the same retinal location between different visits [16]. Likewise, this algorithm computes the number and localization of MA in each visit, allowing the calculation of the MA disappearance and formation rates between visits. MAT is processed as the sum of the MA formation and disappearance rates $[17,18]$. The MAT obtained using both the initial visit and the 6-month visit is considered the baseline MAT.

\section{Optical Coherence Tomography (OCT) and OCT-Angiography}

Optical coherence tomography was performed for each participant at each visit with the Zeiss Cirrus 5000 AngioPlex (Carl Zeiss Meditec, Dublin, CA, USA) using the macular pube
$512 \times 128$ acquisition protocol (128 B-scans with 512 A-scans each) [19].

Average thickness values of CRT and the ganglion cell layer + inner plexiform layer $(G C L+$ IPL) at the inner ring were automatically collected from Zeiss Cirrus standard reports. Decreases (thinning) in GCL + IPL were considered to identify neurodegeneration.

To collect vessel density (VD) metrics on OCT-angiography recordings, the $3 \times 3 \mathrm{~mm}^{2}$ acquisition protocol was performed over a $3 \times 3 \times 2 \mathrm{~mm}^{3}$ volume in the central macula, consisting of a set of 245 clusters of four B-scan repetitions, where each B-scan consists of 245 A-scans [20]. Retinal perfusion density (PD) and VD and the foveal avascular zone (FAZ) detected at the superficial capillary plexus (SCP), deep capillary plexus (DCP), and full retina (FR) were calculated using the Carl Zeiss Meditec Density Exerciser (version:10.0.12787; Carl Zeiss Meditec, Inc., Dublin, CA, USA) [20, 21]. Quality check and normalization of signal strength was carried out in all OCTA examinations as described previously [22].

\section{Characterization of DR Phenotypes}

Classification of DR phenotype for each participant was performed based on the level of MAT and CRT at the 6-month visit, as described previously by our group [7, 14]. As mentioned above, for inclusion criteria, only individuals classified with phenotype $\mathrm{B}$ or $\mathrm{C}$ were followed in the study.

Phenotype classification rules are defined as follows: eyes with MAT $<6$ and normal CRT values are classified as phenotype A; eyes with MAT $<6$ and increased CRT values $(\mathrm{CRT} \geq 260 \mu \mathrm{m}$ in women and $\geq 275 \mu \mathrm{m}$ in men) are classified as phenotype B; and eyes with MAT $\geq 6$, with or without increased CRT, are classified as phenotype C [7]. CRT reference values presented in this study are the reference values for the Zeiss Cirrus 5000 SD-OCT system [23, 24]. 


\section{Statistical Analysis}

Data on each eye/patient are represented as means and corresponding standard deviations for continuous variables and as absolute and relative frequencies for categorical and ordinal variables. Accordingly, a comparison of baseline characteristics between phenotypes (B and C) was performed for categorical variables using the Chi-square test and the Mann-Whitney test for continuous variables, given that data were not normally distributed. Baseline ocular characteristics between participants with phenotypes $\mathrm{B}$ and $\mathrm{C}$ and healthy controls were compared with the Mann-Whitney test. Changes in systemic and ocular characteristics at 1-year follow-up were assessed with the Wilcoxon signed-rank test. The Wilcoxon signedrank test was also applied to analyze changes at 1 year within each phenotype for the same variables. The Kruskal-Wallis test was used to compare systemic and ocular parameters among participants with different ETDRS levels $(10,35$, and $43+47)$.

Data normality was assessed with the Shapiro-Wilk test. All statistical analyses were performed with Stata 16.1 (StataCorp LLC, College Station, TX, USA), and $p$ values $<0.05$ were considered statistically significant.

\section{RESULTS}

From the 133 T2D individuals with NPDR (ETDRS levels 20, 35, and 43-47) included in the study, 128 completed the 1-year follow-up (Fig. 1). Of those, 81 (61\%) were classified as phenotype B and 52 (39\%) classified as phenotype C. During the period of 1 year, 18 T2D individuals developed CIME, including 12 eyes classified as phenotype B and six eyes as phenotype C. Five participants dropped out of the study (two were lost to follow-up and three chose to withdraw from the study).

Demographic, systemic, and ocular characteristics of each phenotype at baseline (except MAT, which was defined at 6-month visit) are described in Table 1 . The population distribution at baseline by phenotype, gender, age, and diabetes duration indicated no attrition bias or deviation due to loss of follow-up, and no significant differences were observed.

Regarding systemic measurements (Table 1), phenotype $C$ presented statistically significant higher levels of HbA1c $(p=0.013)$ and lower levels of HDL cholesterol $(p=0.033)$, but no statistically significant differences were observed in blood pressure levels, body mass index, LDL cholesterol, and triglycerides between the two phenotype populations.

Baseline ETDRS level distribution in each phenotype population is depicted in Table 1, which reveals statistically different values between phenotypes, with phenotype B presenting a higher number of individuals classified with ETDRS level 35, and phenotype C a higher number of individuals with ETDRS $43-47$, representing more severe stages of the disease.

In agreement with the criteria for definition of DR phenotypes, central subfield retinal thickness was increased in phenotype $B$ when compared to phenotype $\mathrm{C}(p<0.001)$. Likewise, phenotype $C$ presented significantly increased MAT values. No statistically significant difference was observed in baseline visual acuity between the two phenotypes (Table 1).

Notably, distinct differences in VD parameters were observed between phenotypes B and C and in relation to the healthy controls. When compared with phenotype $\mathrm{B}$, phenotype $\mathrm{C}$ presented significantly increased capillary closure (lower VD values) at the SCP $(p=0.001)$, DCP $(p=0.005)$, and FR $(p=0.001)$. Furthermore, the FAZ area was significantly different between phenotypes $(p<0.001)$, being decreased only in phenotype C $(p=0.04)$ (Table 1).

When evaluating the 1-year evolution of systemic markers in the study population (Table 2), statistically significant differences were found in the lipid profile, with a decrease in LDL levels $(p<0.001)$ and increase in the levels of HDL $(p<0.001)$. Regarding the ocular markers, there was a significant decrease in the visual acuity in the study population $(0.022 \pm 0.078 ; p=0.007)$ during the 1 -year period of follow-up. Although no significant differences were observed in the CRT, there was a significant thinning of the GCL + IPL layers 


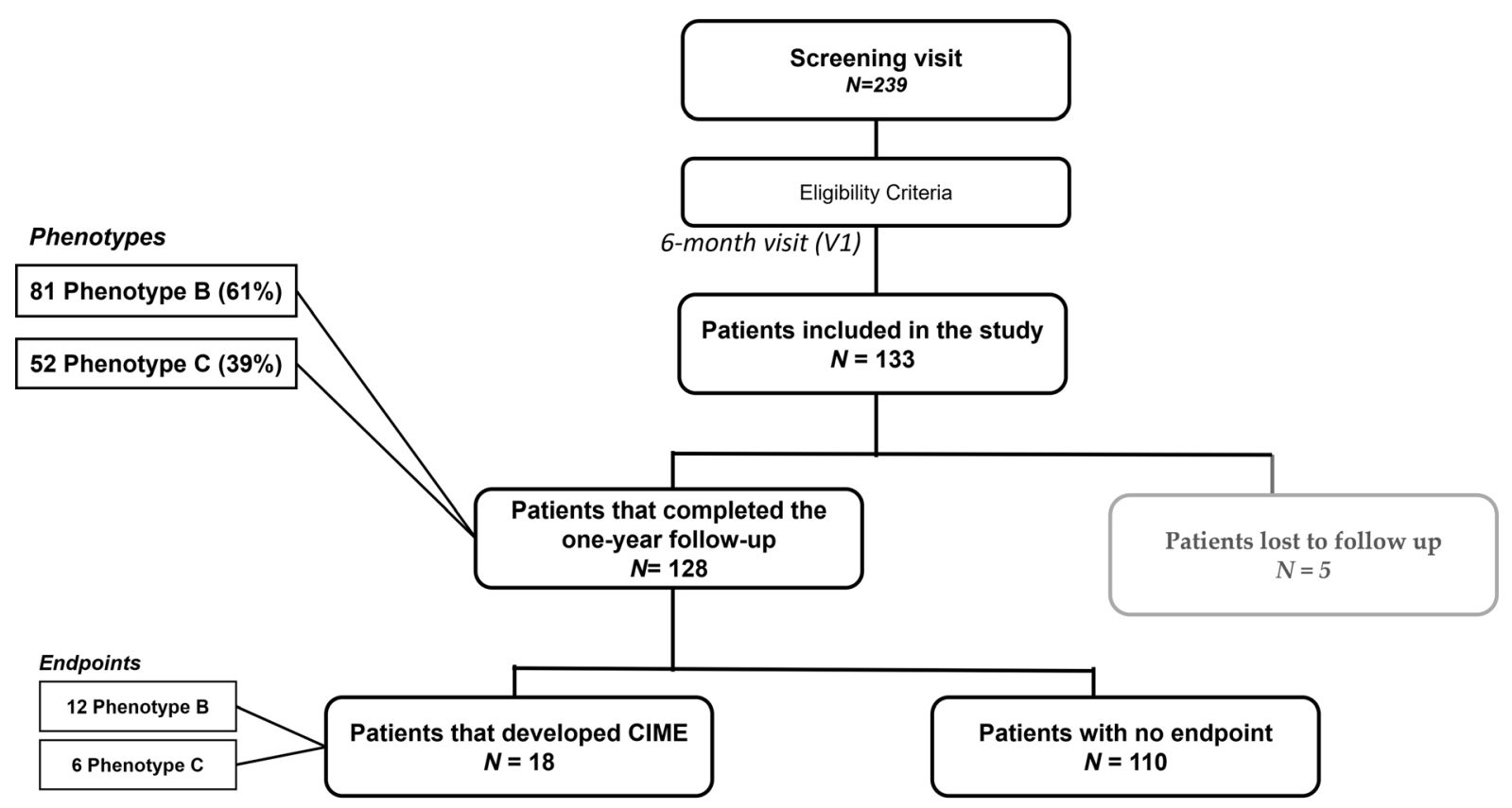

Fig. 1 Cohort flowchart: composition of the patients included in the study over the study period. CIME center-involved macular edema

$(-1.26 \pm 5.99 \mu \mathrm{m} ; p<0.001)$, suggesting that 1 year is sufficient to detect the DR-related neurodegenerative processes. Regarding microvascular changes, there was also a significant decrease in MAT $(-2.41 \pm 4.37, p<0.001)$ and in the VD at the DCP $(-0.888 \pm 2.410$; $p<0.001)$ and in the FAZ area $(-0.019 \pm 0.078$, $p=0.040$ ) (Table 2).

Evaluation of the systemic and ocular variables of phenotypes B and C at baseline (VO) and after 1 year (V2) of follow-up revealed distinct outcomes in some variables that can be used to characterize and differentiate 1-year progression, as shown in Table 3. At the systemic level, phenotype B presented lower LDL and higher HDL levels after 1 year of follow-up $(p<0.001)$, without any other statistically significant change in the evaluated markers. In addition to a significant decrease in LDL levels $(p=0.040)$ and HDL levels $(p<0.001)$, individuals classified with phenotype $C$ also presented significant changes in both systolic and diastolic blood pressure $(p=0.003$ and $p=0.049$, respectively).

Regarding ocular markers, only individuals classified with phenotype $\mathrm{C}$ demonstrated a significant decrease in visual acuity $(p=0.020)$ after 1 year of follow-up. Both phenotypes B and $\mathrm{C}$ presented significant changes in $\mathrm{GCL}+$ IPL thinning $(p<0.001)$, reinforcing the presence of a DR-associated neurodegenerative process in these individuals. Also, MAT was statistically different after 1 year of follow-up in phenotypes B $(p=0.012)$ and C $(p<0.001)$. Interestingly, when looking at MA formation and disappearance rates, both phenotypes exhibited significant changes in MA disappearance over 1 year of follow-up $(p<0.001)$, but only phenotype $C$ showed a significant decrease in the MA formation rate over this period $(p<0.001)$. Also, at the microvascular level, a statistically significant decrease in vascular density at the DCP level was identified in both phenotypes $[\mathrm{B} \quad(p=0.007$ and phenotype $\mathrm{C}$ $(p=0.017)]$, but only phenotype $\mathrm{C}$ showed a significant reduction in the FAZ area $(p=0.036)$ (Table 3).

Finally, analysis of the data obtained at the 1-year visit considering baseline ETDRS levels showed a clear correlation between microvascular changes and DR severity (Table 4), with statistically significant differences in the MAT 
Table 2 Overall 1-year progression in the study population $(N=128)$

\begin{tabular}{|c|c|c|c|c|}
\hline & Baseline (V0) & 1-year (V2) & Mean difference (V2 - V0) & $p$ value \\
\hline \multicolumn{5}{|l|}{ Systemic characteristics, mean $\pm S D$} \\
\hline HbAlc (\%) & $7.7 \pm 1.4$ & $7.6 \pm 1.1$ & $-0.08 \pm 1.11$ & 0.874 \\
\hline Total cholesterol $(\mathrm{mg} / \mathrm{dL})$ & $161.1 \pm 41.2$ & $157.5 \pm 34.0$ & $-3.66 \pm 30.02$ & 0.199 \\
\hline LDL cholesterol $(\mathrm{mg} / \mathrm{dL})$ & $90.3 \pm 32.6$ & $81.7 \pm 28.8$ & $-8.58 \pm 29.37$ & $<0.001$ \\
\hline HDL cholesterol $(\mathrm{mg} / \mathrm{dL})$ & $45.3 \pm 11.5$ & $48.9 \pm 12.6$ & $3.63 \pm 8.1$ & $<0.001$ \\
\hline Triglycerides $(\mathrm{mg} / \mathrm{dL})$ & $128.2 \pm 62.4$ & $131.8 \pm 67.4$ & $3.64 \pm 55.57$ & 0.564 \\
\hline Systolic blood pressure ( $\mathrm{mmHg})$ & $139.0 \pm 11.9$ & $137.0 \pm 13.5$ & $-1.95 \pm 14.81$ & 0.113 \\
\hline Diastolic blood pressure $(\mathrm{mmHg})$ & $72.8 \pm 8.6$ & $71.0 \pm 8.2$ & $-1.73 \pm 8.89$ & 0.023 \\
\hline \multicolumn{5}{|l|}{ Ocular characteristics, mean $\pm S D$} \\
\hline BCVA (logMAR) & $0.01 \pm 0.09$ & $0.035 \pm 0.095$ & $0.022 \pm 0.078$ & 0.007 \\
\hline $\mathrm{CRT}(\mu \mathrm{m})$ & $277.1 \pm 19.4$ & $278.6 \pm 23.8$ & $1.57 \pm 15.28$ & 0.871 \\
\hline GCL + IPL thickness $(\mu \mathrm{m})$ & $79.9 \pm 8.0$ & $78.6 \pm 9.5$ & $-1.26 \pm 5.99$ & $<0.001$ \\
\hline MA turnover ${ }^{a}$ & $5.2 \pm 6.3$ & $2.7 \pm 3.8$ & $-2.41 \pm 4.37$ & $<0.001$ \\
\hline Vessel density: inner ring-SCP $\left(\mathrm{mm}^{-1}\right)$ & $20.6 \pm 1.4$ & $20.6 \pm 1.4$ & $-0.084 \pm 1.050$ & 0.369 \\
\hline Vessel density: inner ring-DCP $\left(\mathrm{mm}^{-1}\right)$ & $15.8 \pm 2.3$ & $15.0 \pm 2.5$ & $-0.888 \pm 2.410$ & $<0.001$ \\
\hline Vessel density: inner ring-FR $\left(\mathrm{mm}^{-1}\right)$ & $22.3 \pm 1.3$ & $22.4 \pm 1.2$ & $0.069 \pm 0.987$ & 0.496 \\
\hline FAZ area $\left(\mathrm{mm}^{2}\right)$ & $0.23 \pm 0.1$ & $0.22 \pm 0.11$ & $-0.019 \pm 0.078$ & 0.040 \\
\hline
\end{tabular}

Bold values represent statistically significant changes, with $p<0.05$, using the Wilcoxon signed-rank test. ${ }^{a}$ Assessed at visit 1 (6 months)

$N$ number of participants, $S D$ standard deviation, $B C V A$ best-corrected visual acuity, $C R T$ central retinal thickness, ETDRS Early Treatment Diabetic Retinopathy Study, GCL + IPL ganglion cell layer + inner plexiform layer, $L D L$ low-density lipoprotein, $H D L$ high-density lipoprotein, $F R$ full retina, $D C P$ deep capillary plexus, $S C P$ superior capillary plexus, $F A Z$ foveal avascular zone, $H b A l c$ glycated hemoglobin

between ETDRS levels 20, 35, and $43+47$ $(p<0.001)$, with the MAT higher in the more severe DR levels. Also, a significant increase in vessel closure was associated with worsening of DR severity, with statistically significant VD decreases observed in the DCP $(p=0.006)$.

\section{DISCUSSION}

This 1-year longitudinal study in individuals with T2D and NPDR (ETDRS levels 20 to 47) classified as belonging to DR phenotypes $\mathrm{B}$ and $\mathrm{C}$, previously shown to be associated with a higher risk of developing vision-threatening complications [8] and DR severity progression [9], confirms and extends our previous studies.

An initial comparison of the two risk phenotypes revealed that phenotype $C$ presents distinctive features from phenotype $B$, such as higher levels of HbA1c, which has been highly associated with DR progression [5]. At an ocular level, and of high relevance, phenotype $C$ presented more noticeable decrease in VD, suggesting that individuals characterized with this phenotype exhibit greater changes in the retinal microvasculature structure, namely, increased capillary closure. 
Table 3 Systemic and ocular changes over 1 year of follow-up $(N=128)$, separated by phenotype

\begin{tabular}{|c|c|c|c|c|c|c|}
\hline & \multicolumn{3}{|c|}{ Phenotype B $(N=78)$} & \multicolumn{3}{|c|}{ Phenotype C $(N=50)$} \\
\hline & Baseline (V0) & 1 year (V2) & $p$ value & Baseline (V0) & 1 year $(\mathrm{V} 2)$ & $p$ value \\
\hline \multicolumn{7}{|c|}{ Systemic characteristics, mean $\pm S D$} \\
\hline HbAlc (\%) & $7.46 \pm 1.32$ & $7.48 \pm 1.01$ & 0.564 & $8.02 \pm 1.4$ & $7.81 \pm 1.13$ & 0.654 \\
\hline Total cholesterol (mg/dL) & $166.36 \pm 43.12$ & $160.31 \pm 33.75$ & 0.079 & $153 \pm 37.01$ & $153.08 \pm 34.15$ & 0.820 \\
\hline LDL cholesterol $(\mathrm{mg} / \mathrm{dL})$ & $94.18 \pm 34.35$ & $83.63 \pm 29.58$ & $<0.001$ & $84.14 \pm 28.91$ & $78.64 \pm 27.68$ & 0.040 \\
\hline HDL cholesterol $(\mathrm{mg} / \mathrm{dL})$ & $47.12 \pm 11.27$ & $50.23 \pm 12.71$ & $<0.001$ & $42.36 \pm 11.42$ & $46.8 \pm 12.17$ & $<0.001$ \\
\hline Triglycerides (mg/dL) & $125.27 \pm 56.15$ & $129.6 \pm 60.87$ & 0.709 & $132.74 \pm 71.39$ & $135.3 \pm 77.04$ & 0.610 \\
\hline $\begin{array}{l}\text { Systolic blood pressure } \\
\qquad(\mathrm{mmHg})\end{array}$ & $138.88 \pm 11.8$ & $138.82 \pm 13.27$ & 0.626 & $139.14 \pm 12.24$ & $134.26 \pm 13.4$ & 0.003 \\
\hline $\begin{array}{l}\text { Diastolic blood pressure } \\
\qquad(\mathrm{mmHg})\end{array}$ & $73.33 \pm 9.14$ & $71.76 \pm 8.05$ & & $71.86 \pm 7.53$ & $69.9 \pm 8.3$ & 0.049 \\
\hline \multicolumn{7}{|c|}{ Ocular characteristics, mean $\pm S D$} \\
\hline BCVA (logMAR) & $0.006 \pm 0.077$ & $0.026 \pm 0.081$ & 0.098 & $0.022 \pm 0.096$ & $0.048 \pm 0.112$ & 0.020 \\
\hline $\mathrm{CRT}(\mu \mathrm{m})$ & $283.28 \pm 13.79$ & $284.27 \pm 21.17$ & 0.451 & $267.34 \pm 22.85$ & $269.82 \pm 25.17$ & 0.610 \\
\hline $\mathrm{GCL}+\mathrm{IPL}$ thickness $(\mu \mathrm{m})$ & $80.71 \pm 7.46$ & $79.96 \pm 8.19$ & $<0.001$ & $78.56 \pm 8.8$ & $76.5 \pm 11$ & $<0.001$ \\
\hline MA turnover & $1.33 \pm 1.61$ & $0.79 \pm 1.22$ & 0.012 & $11.1 \pm 6.34$ & $5.77 \pm 4.31$ & $<0.001$ \\
\hline MA formation rate & $0.70 \pm 1.15$ & $0.49 \pm 0.88$ & 0.257 & $6.30 \pm 4.64$ & $3.63 \pm 3.36$ & $<0.001$ \\
\hline MA disappearance rate & $0.64 \pm 1.03$ & $0.30 \pm 0.63$ & $<0.001$ & $4.80 \pm 3.71$ & $2.41 \pm 2.00$ & $<0.001$ \\
\hline $\begin{array}{l}\text { Vessel density: inner ring- } \\
\text { SCP }\left(\mathrm{mm}^{-1}\right)\end{array}$ & $21.06 \pm 1.06$ & $20.97 \pm 1.14$ & 0.467 & $20.04 \pm 1.63$ & $20.02 \pm 1.47$ & 0.509 \\
\hline $\begin{array}{l}\text { Vessel density: inner ring- } \\
\text { DCP }\left(\mathrm{mm}^{-1}\right)\end{array}$ & $16.26 \pm 2.02$ & $15.55 \pm 2.20$ & 0.007 & $15.07 \pm 2.49$ & $14.05 \pm 2.68$ & 0.013 \\
\hline $\begin{array}{l}\text { Vessel density: inner ring- } \\
\text { FR }\left(\mathrm{mm}^{-1}\right)\end{array}$ & $22.73 \pm 1.05$ & $22.79 \pm 1.04$ & 0.678 & $21.76 \pm 1.48$ & $21.86 \pm 1.34$ & 0.679 \\
\hline FAZ area $\left(\mathrm{mm}^{2}\right)$ & $0.20 \pm 0.08$ & $0.20 \pm 0.09$ & 0.387 & $0.28 \pm 0.10$ & $0.25 \pm 0.12$ & 0.036 \\
\hline
\end{tabular}

Bold values represent statistically significant changes, with $p<0.05$, using the Wilcoxon signed-rank test

$N$ number of participants, $B C V A$ best-corrected visual acuity, CRT central retinal thickness, ETDRS Early Treatment Diabetic Retinopathy Study, GCL + IPL ganglion cell layer + inner plexiform layer, $L D L$ low-density lipoprotein, $H D L$ high-density lipoprotein, $F R$ full retina, $D C P$ deep capillary plexus, $S C P$ superior capillary plexus, $F A Z$ foveal avascular zone, HbAlc glycated hemoglobin

Interestingly, although both phenotypes B and $\mathrm{C}$ developed similar rates of vision-threatening complications, namely CIME, phenotype $\mathrm{C}$ was systemically characterized by more significant changes in the lipid profile and blood pressure and, at the ocular level, a decrease in visual acuity and higher progression of microvascular changes. Similarly, 1-year progression was better identified in eyes with higher severity grading. 
Table 4 Systemic and ocular parameters at month 12 visit, by ETDRS level

\begin{tabular}{|c|c|c|c|c|}
\hline One-year follow-up (V2) & $\begin{array}{l}\text { ETDRS } 20 \\
(N=13)\end{array}$ & $\begin{array}{l}\text { ETDRS } 35 \\
(N=76)\end{array}$ & $\begin{array}{l}\text { ETDRS } 43+47 \\
(N=39)\end{array}$ & $p$ value \\
\hline \multicolumn{5}{|l|}{ Systemic characteristics, mean $\pm S D$} \\
\hline HbAlc (\%) & $7.0 \pm 0.8$ & $7.6 \pm 1.0$ & $7.9 \pm 1.2$ & 0.034 \\
\hline Total cholesterol (mg/dL) & $158.1 \pm 32$ & $155.5 \pm 30.2$ & $161.2 \pm 41.4$ & 0.899 \\
\hline LDL cholesterol $(\mathrm{mg} / \mathrm{dL})$ & $78.9 \pm 25.3$ & $81.0 \pm 27.2$ & $84 \pm 33.3$ & 0.866 \\
\hline HDL cholesterol (mg/dL) & $52.6 \pm 14.3$ & $49.3 \pm 12.1$ & $46.9 \pm 12.9$ & 0.347 \\
\hline Triglycerides $(\mathrm{mg} / \mathrm{dL})$ & $132.9 \pm 86.7$ & $121.6 \pm 56$ & $151.4 \pm 77.6$ & 0.211 \\
\hline Systolic blood pressure $(\mathrm{mmHg})$ & $139.1 \pm 9.7$ & $137.5 \pm 14.1$ & $135.5 \pm 13.3$ & 0.641 \\
\hline Diastolic blood pressure $(\mathrm{mmHg})$ & $74.6 \pm 6.4$ & $70.8 \pm 8.3$ & $70.2 \pm 8.3$ & 0.187 \\
\hline \multicolumn{5}{|l|}{ Ocular characteristics, mean $\pm S D$} \\
\hline BCVA (logMAR) & $-0.01 \pm 0.07$ & $0.04 \pm 0.09$ & $0.04 \pm 0.11$ & 0.271 \\
\hline $\mathrm{CRT}(\mu \mathrm{m})$ & $280.0 \pm 17.8$ & $279.3 \pm 25.7$ & $276.8 \pm 22.1$ & 0.781 \\
\hline GCL + IPL thickness $(\mu \mathrm{m})$ & $83.1 \pm 5.6$ & $78.7 \pm 8.7$ & $76.9 \pm 11.5$ & 0.088 \\
\hline MA turnover & $0.9 \pm 1.0$ & $1.5 \pm 2.0$ & $5.8 \pm 5.0$ & $<0.001$ \\
\hline $\begin{array}{l}\text { Vessel density: inner ring-SCP } \\
\left(\mathrm{mm}^{-1}\right)\end{array}$ & $20.89 \pm 1.09$ & $20.70 \pm 1.44$ & $20.32 \pm 1.25$ & 0.177 \\
\hline $\begin{array}{l}\text { Vessel density: inner ring-DCP } \\
\left(\mathrm{mm}^{-1}\right)\end{array}$ & $15.99 \pm 2.24$ & $15.32 \pm 2.44$ & $13.98 \pm 2.44$ & 0.006 \\
\hline $\begin{array}{l}\text { Vessel density: inner ring_-FR } \\
\left(\mathrm{mm}^{-1}\right)\end{array}$ & $22.79 \pm 1.00$ & $22.54 \pm 1.34$ & $22.12 \pm 1.09$ & 0.096 \\
\hline FAZ area $\left(\mathrm{mm}^{2}\right)$ & $0.19 \pm 0.09$ & $0.21 \pm 0.10$ & $0.24 \pm 0.12$ & 0.351 \\
\hline
\end{tabular}

Bold values represent statistically significant changes, with $p<0.05$, using the Kruskal-Wallis test

$N$ number of participants, $S D$ standard deviation, $B C V A$ best-corrected visual acuity, $C R T$ central retinal thickness, ETDRS Early Treatment Diabetic Retinopathy Study, GCL + IPL ganglion cell layer + inner plexiform layer, $L D L$ low-density lipoprotein, $H D L$ high-density lipoprotein, $F R$ full retina, $D C P$ deep capillary plexus, $S C P$ superior capillary plexus, $F A Z$ foveal avascular zone, $H b A 1 c$ glycated hemoglobin

Phenotype C, characterized by more marked microvascular changes, is associated with more rapid disease progression, enabling the detection of eyes that show more significant changes in the microvascular OCTA metrics over a period of 1 year. Also, retinal disease progression, namely capillary closure in the DCP, over a period of 1 year is more readily identified in more advanced ETDRS severity grades, such as 43 and 47. Our data show that the combination of the risk phenotype characteristics together with the ETDRS severity grade may contribute to improving identification of eyes at risk.

Another relevant finding is the observation that retinal neurodegeneration is present in both phenotypes. Retinal neurodegeneration may function as a trigger for the development of microvascular changes in phenotype $\mathrm{C}$ (increased MAT), and for the alteration of the blood-retinal barrier and edema that characterize phenotype B (increased CRT). The different phenotypes may, indeed, be the result of 
different responses in different patients to the neurodegenerative changes occurring in the retina as a result of chronic hyperglycemia and diabetes [25].

It is also relevant that the 1-year progression registered in vessel closure was identified in the deep retinal capillary layer. As previously shown, it appears that in initial stages of DR, the capillary closure is better identified in the superficial capillary layer and in the macular area, involving alteration of the FAZ [20], but subsequent progression of the retinal vascular disease appears to occur mainly through changes involving the DCP [26].

The findings described herein contribute to improving our understanding of DR progression. A 1-year follow-up interval for eyes in the initial stages of DR is apparently not long enough to identify clinical changes of major relevance, but offers information that is of value to improve the design of clinical trials aiming to test the effect of drugs to prevent DR progression.

A limitation of this study is the focus on the initial stages of DR, allowing conclusions to be made on 1-year progression of changes occurring in eyes of people with T2D with ETDRS levels 20, 35, and 43-47. However, the use of these criteria guaranteed a relatively homogeneous population. Another limitation is the relatively small number of people included in the study and the type of population that is enrolled in clinical trials to test new therapeutic options. However, the phenotype characterization and direct comparison between them is of major value and offers new insights into the progression of retinal diabetic disease.

In summary, DR appears to be characterized by the presence of progressive neurodegenerative changes that in some patients lead to a deficient microvascular response characterized by progressive vascular closure and ischemia and in others lead to an alteration of the blood-retinal barrier and increased thickening of the retina.

The observations reported herein offer promising perspectives for personalized management of DR. After diagnosis of NPDR and still in the initial stages of retinal disease, different phenotypes can be identified through fundus photography and OCT. These examinations are easy to perform and can be repeated easily without major inconvenience to the patient. This study confirms their value for improved characterization of disease progression allowing better identification of eyes at risk for progression and development of visionthreatening complications.

The retinopathy phenotypes identified in people with T2D show not only different risks for vision-threatening complications, as demonstrated in previous studies $[8,9]$ but also allow short-term identification and characterization of NPDR disease progression. Phenotype $B$ is a slow progression phenotype that is adequately followed at relatively larger intervals, suggesting that examination intervals longer than 1 year are acceptable. On the other hand, people with T2D presenting phenotype C (characterized by vessel closure and ischemia) should receive frequent attention and examinations may be needed at shorter intervals than 1 year.

\section{CONCLUSIONS}

The distinct inter-individual progression of retinopathy in T2D individuals is one of the major concerns when defining therapeutic strategies. The data presented herein reinforce the idea that using the classification of retinopathy phenotypes in $\mathrm{T} 2 \mathrm{D}$ individuals might be a useful tool to facilitate a more personalized approach, as phenotype $\mathrm{C}$, characterized by predominant microvascular changes, identifies eyes at higher risk for disease progression particularly in more advanced stages of the disease. Individuals classified as phenotype $\mathrm{C}$ at the time of diagnosis should therefore have more frequent follow-up, enabling timely therapeutic interventions.

\section{ACKNOWLEDGEMENTS}

Funding. This work was supported by AIBILI, COMPETE Portugal2020, Foundation for Science and Technology (Project no: 02/SAICT/ 
2017-032412) and the Fundo de Inovação, Tecnologia e Economia Circular (FITEC)-Programa Interface (FITEC/CIT/2018/2). No funding or sponsorship was received for publication of this article.

Authorship. All named authors meet the International Committee of Medical Journal Editors (ICMJE) criteria for authorship for this article, take responsibility for the integrity of the work as a whole, and have given their approval for this version to be published.

Author Contributions. LR, IPM, and ARS performed the study, collected data, and wrote, reviewed, and edited the manuscript. MHM, RAC, and TS analyzed the data and contributed to writing and editing the manuscript. PB supported and managed the realization of the clinical study. CL assisted in the analysis and reviewed and edited the manuscript. JC-V analyzed the data and wrote the manuscript. JC-V and LR are the guarantors of this work and, as such, had full access to all the data in the study and take responsibility for the integrity of the data and the accuracy of the data analysis. All authors have read and agreed to the published version of the manuscript. The authors acknowledge ML, SS, PB, JF, and RS for their support and contributions throughout the study development.

Disclosures. Luísa Ribeiro, Inês P. Marques, Rita A Coimbra, Torcato Santos, Maria H Madeira, Ana Rita Santos, Patrícia Barreto, and Conceição Lobo all have nothing to disclose. Jose Cunha-Vaz reports grants from Carl Zeiss Meditec outside the submitted work and is consultant for Alimera Sciences, Allergan, Bayer, Gene Signal, Novartis, Pfizer, Precision Ocular Ltd., Roche, Sanofi-Aventis, Vifor Pharma, and Carl Zeiss Meditec.

Compliance with Ethics Guidelines. The tenets of the Declaration of Helsinki were followed, and the study was reviewed and approved by the AIBILI'S Ethics Committee for Health with the number CEC/194/18 (CORDIS), NCT 03696810. A written informed consent was signed by each participant signed, agreeing to participate in the study, after all procedures were explained.

Data Availability. The datasets generated during and/or analyzed during the current study are available from the corresponding author on reasonable request.

Open Access. This article is licensed under a Creative Commons Attribution-NonCommercial 4.0 International License, which permits any non-commercial use, sharing, adaptation, distribution and reproduction in any medium or format, as long as you give appropriate credit to the original author(s) and the source, provide a link to the Creative Commons licence, and indicate if changes were made. The images or other third party material in this article are included in the article's Creative Commons licence, unless indicated otherwise in a credit line to the material. If material is not included in the article's Creative Commons licence and your intended use is not permitted by statutory regulation or exceeds the permitted use, you will need to obtain permission directly from the copyright holder. To view a copy of this licence, visit http://creativecommons.org/licenses/by$\mathrm{nc} / 4.0 /$.

\section{REFERENCES}

1. Cheung N, Mitchell P, Wong TY. Diabetic retinopathy. Lancet. 2010;376:124-36.

2. Narayan KMV, Boyle JP, Geiss LS, Saaddine JB, Thompson TJ. Impact of recent increase in incidence on future diabetes burden: U.S., 2005-2050. Diabetes Care. 2006;29:2114-6.

3. Cunha-Vaz J, Ribeiro L, Lobo C. Phenotypes and biomarkers of diabetic retinopathy. Prog Retin Eye Res. 2014;41:90-111.

4. Hove MN, Kristensen JK, Lauritzen T, Bek T. The relationships between risk factors and the distribution of retinopathy lesions in type 2 diabetes. Acta Ophthalmol Scand. 2006;84:619-23.

5. Atchison E, Barkmeier A. The role of systemic risk factors in diabetic retinopathy. Curr Ophthalmol Rep. 2016;4(2):84-9. 
6. Martinho AC-V, Marques IP, Messias AL, Santos T, Madeira MH, Sousa DC, et al. Ocular and systemic risk markers for development of macular edema and proliferative retinopathy in type 2 diabetes: a 5-year longitudinal study. Diabetes Care. 2020;44: dc201125.

7. Nunes S, Ribeiro L, Lobo C, Cunha-Vaz J. Three different phenotypes of mild nonproliferative diabetic retinopathy with different risks for development of clinically significant macular edema. Investig Ophthalmol Vis Sci. 2013;10:4595-604.

8. Marques IP, Madeira MH, Messias AL, Santos $\mathrm{T}$, Martinho AC-V, Figueira J, et al. Retinopathy phenotypes in type 2 diabetes with different risks for macular edema and proliferative retinopathy. J Clin Med. 2020;9(5):1433.

9. Marques IP, Madeira $\mathrm{MH}$, Messias $\mathrm{AL}$, Martinho ACV, Santos T, Sousa DC, et al. Different retinopathy phenotypes in type 2 diabetes predict retinopathy progression. Acta Diabetol. 2021;58(2): 197-205.

10. Grading Diabetic Retinopathy from Stereoscopic Color Fundus Photographs-An Extension of the Modified Airlie House Classification: ETDRS Report Number 10. Ophthalmology. 2020;127(4S):S9: S99-119.

11. Friedman SM, Almukhtar TH, Baker CW, Glassman AR, Elman MJ, Bressler NM, et al. Topical nepafenec in eyes with noncentral diabetic macular edema. Retina. 2015;35:944-56.

12. Ribeiro L, Bandello F, Tejerina AN, Vujosevic S, Varano M, Egan C, et al. Characterization of retinal disease progression in a 1-year longitudinal study of eyes with mild nonproliferative retinopathy in diabetes type 2. Investig Ophthalmol Vis Sci. 2015;56:5698-705.

13. Ribeiro ML, Nunes SG, Cunha-Vaz JG. Microaneurysm turnover at the macula predicts risk of development of clinically significant macular edema in persons with mild nonproliferative diabetic retinopathy. Diabetes Care. 2013;36(5):1254.

14. Ribeiro L, Pappuru R, Lobo C, Alves D, Cunha-Vaz J. Different phenotypes of mild nonproliferative diabetic retinopathy with different risks for development of macular edema (C-TRACER Study). Ophthalmic Res. 2018;59:59-67.

15. Khoshnood B, Mesbah M, Jeanbat V, Lafuma A, Berdeaux G. Transforming scales of measurement of visual acuity at the group level. Ophthalmic Physiol Opt. 2010;30(6):816-23.
16. Santos AR, Mendes L, Madeira MH, Marques IP, Tavares D, Figueira J, et al. Microaneurysm turnover in mild non-proliferative diabetic retinopathy is associated with progression and development of vision-threatening complications: a 5-year longitudinal study. J Clin Med. 2021;10(10):214.

17. Figueiredo IN, Kumar S, Oliveira CM, Ramos JD, Engquist B. Automated lesion detectors in retinal fundus images. Comput Biol Med. 2015;66:47-65.

18. Bernardes R, Nunes S, Pereira I, Torrent T, Rosa A, Coelho D, et al. Computer-assisted microaneurysm turnover in the early stages of diabetic retinopathy. Ophthalmologica. 2009;223(5):284.

19. Santos AR, Alves D, Santos T, Figueira J, Silva R, Cunha-Vaz JG. Measurements of retinal fluid by optical coherence tomography leakage in diabetic macular edema: a biomarker of visual acuity response to treatment. Retina. 2019;39:52-60.

20. Durbin MK, An L, Shemonski ND, Soares M, Santos $\mathrm{T}$, Lopes $\mathrm{M}$, et al. Quantification of retinal microvascular density in optical coherence tomographic angiography images in diabetic retinopathy. JAMA Ophthalmol. 2017;135:370.

21. Marques IP, Kubach S, Santos T, Mendes L, Madeira $\mathrm{MH}$, de Sisternes $\mathrm{L}$, et al. Optical Coherence Tomography Angiography metrics monitor severity progression of Diabetic Retinopathy-3-year longitudinal study. J Clin Med. 2021;0(11):2296.

22. Lei J, Durbin MK, Shi Y, Uji A, Balasubramanian S, Baghdasaryan E, et al. Repeatability and reproducibility of superficial macular retinal vessel density measurements using optical coherence tomography angiography en face images. JAMA Ophthalmol. 2017;135:1092.

23. Lobo C, Pires I, Alves D, Pappuru R, Ribeiro L, Cunha-Vaz J. Subclinical macular edema as a predictor of progression to central-involved macular edema in type 2 diabetes. Ophthalmic Res. 2018;60(1):18-22.

24. Friedman SM, Almukhtar TH, Baker CW, Glassman AR, Elman MJ, Bressler NM, et al. Topical nepafenac in eyes with noncentral diabetic macular edema. Retina. 2015;35:944-56.

25. Simó R, Stitt AW, Gardner TW. Neurodegeneration in diabetic retinopathy: does it really matter? Diabetologia. 2018;61(9):1902-12.

26. Santos T, Warren LH, Santos AR, Marques IP, Kubach S, Mendes LG, et al. Swept-source OCTA quantification of capillary closure predicts ETDRS severity staging of NPDR. $\mathrm{Br} \mathrm{J}$ Ophthalmol. 2020;10:1-7. 